\title{
Travma Sonrası Stres Bozukluğunun Tedavisinde EEG-Dayalı Nörofeedback Yönteminin Kullanımı
}

\begin{abstract}
Anzel BAHADIR 國 1
ÖZ

Travma Sonrası Stres Bozukluğu, hayatı tehdit edici travmatik olayları takiben gelişebilen mental bir bozukluktur. Elektroensefalografi dayalı nörofeedback, farklı bilinç ve duygu durumlarına özgü elektroensefalografi dalga aktivitesi modellerinin, kişinin istenilen becerileri elde etmesi için edimsel (operant) koşullanma çerçevesi içinde biyofeedback yolu ile değiştirilmesini amaçlayan, girişimsel olmayan bir yöntemdir. Bu yöntem, travma sonrası stres bozukluğunu da içeren birçok nöropskiyatrik hastalıklarda alternatif tedavi yöntemi olarak kullanılmaktadır. Bu derlemede, travma sonrası stres bozukluğu tedavisinde elektroensefalografi dayalı nörofeedback yöntemin etkinliğini değerlendirmek için, Pubmed, EMBASE, EBSCOhost, ULAKBİM veri tabanları taranmış ve farklı nörofeedback tedavi protokolleri kullanan 14 çalışma incelenmiştir. $\mathrm{Bu}$ inceleme sonucu, farklı tedavi protokollerine bağlı olarak, özgün olası etki mekanizmaları üzerinden elektroensefalografi dayalı nörofeedback yönteminin uygulanmasının, travma sonrası stres bozukluğu tedavisi ve semptomlarının iyileştirilmesi üzerinde anlamlı derecede olumlu etkiler gösterdiği belirlenmiştir. Elektroensefalografi dayalı nörofeedback yöntemimin, travma sonrası stres bozukluğu tedavisi üzerinde kesin etki mekanizmalarını ortaya koyabilmek ve bireye ve/veya hastalığın semptomlarına özgü standardize tedavi protokollerini belirleyebilmek, ilaç kullanımı, terapist-hasta özellikleri ve diğer terapötik süreçleri gibi travma sonrası stres bozukluğu tedavisine etki edebilecek diğer faktörleri de hesaba katarak, elektroensefalografi dayalı nörofeedback tedavisinin uzun süreli olumlu etkisinin araştırılmasına yönelik, daha kapsamlı kontrollü çalışmaların yapılması hedeflenmelidir.
\end{abstract}

Anahtar Kelimeler: Elektroensefalografi biyofeedback; nörofeedback; tedavi protokolleri; travma sonrası stres bozukluğu; psikoterapi.

\section{The Use of EEG-Based Neurofeedback Method in the Treatment of Posttraumatic Stress Disorder}

\section{ABSTRACT}

Post-traumatic stress disorder is a mental disorder that can develop following life-threatening traumatic events. Electroencephalography-based neurofeedback is a non-invasive method that aims to modify electroencephalography wave activity patterns specific to different states of consciousness and emotion by biofeedback within the framework of operant conditioning to achieve the desired skills. This method is used as an alternative treatment for many neuropsychiatric diseases involving post-traumatic stress disorder. In this review, Pubmed, EMBASE, EBSCOhost, ULAKBIM databases were searched and 14 studies were evaluated using different neurofeedback treatment protocols to evaluate the effectiveness of electroencephalography-based neurofeedback method in the treatment of post-traumatic stress disorder. Findings showed that electroencephalography-based neurofeedback method has significantly different positive effects on the treatment of post-traumatic stress disorder and the improvement of symptoms depending on specific treatment protocols. More comprehensive controlled studies should be aimed at intended for sustained positive effect of electroencephalography-based neurofeedback treatment to put forward the exact mechanisms of electroencephalographybased neurofeedback method on post-traumatic stress disorder treatment and to determine standardized treatment protocols specific to the individual and /or symptoms of the disorder, also taking into using medication therapist-patient characteristics, and other therapeutic processes, including other factors that may affect post- traumatic stress disorder treatment.
\end{abstract}

Keyword: Electroencephalography biofeedback; neurofeedback; treatment protocols; post-traumatic stress disorder; psychotherapy. 


\section{GíRiş}

Nörofeedback (NF), özgün bir biyofeedback (biyogeribildirim) türü olup, beyin sinyallerinin kendi-kendini düzenlemesi ve kontrolünü öğrenmesi için kişiye kendine dönük olarak geribildirim (feedback) vermesi sonucu kişinin birçok beyin sinyallerini iyileştirmek için kullanılan davranışsal bir eğitim şeklidir. Bu eğitim şekli, gerçek zamanlı (real-time) olarak genellikle görsel ve/veya işitsel ya da bunların kombinasyonu geribildirim sağlayarak nörolojik regülasyonu ve stabilizasyonu geliştirmek için beyin ve merkezi sinir sitemine (MSS) odaklanır. $\mathrm{Bu}$ yöntemde, istenmeyen beyin aktiviteleri, negatif feedback ile baskılanır iken, istenilen beyin aktiviteleri pozitif feedback ile güçlendirilir. Herhangi bir riski ya da yan etkisi olmayan bu eğitim yönteminde edimsel (operant) şartlanma ile kişi kendi beynini kontrol etmesini öğrenmektedir (1).

Bu yöntem, beyin-bilgisayar arayüzünü kullanarak beyin dalgalarını düzenlemeye yardımcı olabilmektedir. Normal dalga modelindeki sapma miktarı, kantitatif EEG (quantitative EEG: qEEG) ile belirlenmektedir (2). Hastalığın şiddetine bağlı olarak, elektrotlar baş ve kulakların farklı bölgelerine bağlanır. $\mathrm{Bu}$ elektrotlar bilgisayara dalgalar gönderir. Bilgisayar sinyalleri, dalgaları ve görüntüleri işler ve sonra onları terapist veya hasta/danışana gösterir. EEG'de istenilen frekanslara doğru bir eğilim gözlendiğinde, deneğe ödüllendirici bir uyaran uygulanır. Bu uyaran, genellikle bir bilgisayar oyunu ve film olarak hasta/danışana gönderilir $(3,4)$. Dolayısıyla, NF, bilgisayar teknolojisi kullanılarak zayıf olarak düzenlenen beyin dalga modellerini iyileştirmek için hastalara eğitim uygulanması yöntemidir (5). Bu eğitimde, etkin sonuç alabilmek için 20-40 dakikalık haftada en az üç kez olarak toplamda 100 seans uygulanmalidir (1).

NF protokolleri; elektroensefalografi (electroencephalography: EEG) magnetoensefalografi (magnetoencephalography: MEG) (6), fonksiyonel manyetik rezonans görüntüleme (functional magnetic resonance imaging: fMRI) (7) ve yakın-infrared spektroskopi (near infrared spectroscopy: NIRS) (8) ve bu cihazların kombinasyonlarını (9) içeren girişimsel olmayan (non-invasive) kayıt tekniklerini kullanmıştır. Bu protokollerden EEG dayalı NF (EEG biyofeedback; nöroterapi), saçlı deri üzerine yerleştirilen elektrotlar aracığıyla kaydedilen çeşitli elektriksel beyin aktivitelerinin göstergesi olan farklı bilinç ve duygu durumlarına özgü EEG dalga aktivitesi modellerinin, kişinin istenilen becerileri elde etmesi için edimsel (operant) koşullanma çerçevesi içinde biyofeedback yolu ile değiştirilmesini amaçlayan, çeşitli hastalıkların tedavisi için yararlanılan alternatif bir yöntemdir (10-12). Dolayısıyla EEG-NF yöntemi, beyin aktivitesinin belirli filtrelenmiş frekanslarının güç spektrumlarını değiştirmek için kullanılmaktadır (13). Bu yöntemin; dikkat eksikliğihiperaktivite bozukluğu, travma sonrası stres bozukluğu, obsesif kompulsif bozukluk, otizm spektrum bozukluğu, majör depresif bozukluk, sosyal fobi veya sosyal anksiyete bozukluğu, yeme bozuklukları (anoreksiya nevroza), öğrenme güçlükleri (disleksi, diskalkuli), uykusuzluk (insomnia), ilaç bağımlılığı, ağrı yönetimi, panik atak, depresyon, anksiyete, epilepsi, şizofren gibi birçok nöro-psikiyatrik hastalıklarda tedavi edici rolüne ilişkin birçok çalışma bulunmaktadır (1,14-27).

Travma Sonrası Stres Bozukluğu (TSSB), hayatı tehdit edici travmatik olayları takiben gelişen ve kişide yoğun korku ve çaresizlik durumu ile karakterize edilen, kişiyi kuvvetten düşüren mental bir bozukluktur. DSM-5 (Amerikan Psikiyatri Birliği Ruhsal Bozuklukların Tanısal ve İstatistiksel El Kitabı'nın beşinci baskısı; The Diagnostic and Statistical Manual of Mental Disorders, Fifth Edition by the American Psychiatric Association (APA)) tanı ölçütlerine göre TSSB, travmatik olayın yeniden yaşantılanması, travma ile ilişkili uyarıdan kaçınma, duygudurum ve bilişte genel değişiklikler ve aşırı uyarılmışlık olarak ifade edilen dört semptom grubu ile tanımlanan heterojen bir hastalıktır $(13,28)$. TSSB için travma-ilişkili uyarıya maruz bırakma ile ilgili olan maruz bırakma terapisi en yaygın kullanılan tedavi yöntemlerinden biri olmasına rağmen, bu tedavi şekli hastaya/danışana oldukça acı/üzüntü verici bir süreçtir (29). Bu nedenle, TSSB için yeni tedavi yöntemlerinin geliştirilmesine ihtiyaç duyulmaktadır. NF, bu acıya/üzüntüye neden olmaksızın TSSB semptomlarını iyileştirmede ümit verici alternatif bir tedavi yaklaşımıdır (13). Feedback seansları boyunca tekrarlayıcı olarak indüklenen TSSB-ilişkili beyin aktivitelerinin spontan meydana gelme frekansları, bu seanslar sonrası değişebilmektedir $(17,21)$.

$\mathrm{Bu}$ derlemenin amacı, güncel literatüre bağlı olarak TSSB tedavisinde EEG-dayalı NF yöntemin yeri ve kullanımını değerlendirmektir. $\mathrm{Bu}$ amaçla Pubmed, EMBASE, EBSCOhost, ULAKBİM, veri tabanları "Travma Sonras1 Stres Bozukluğu (TSSB)', 'Neurofeedback (NF)", "Elektroensafalografi (EEG) dayalı Neurofeedback (EEG-NF)', EEG biyofeedback”, “EEG-NF tedavi protokolleri', anahtar kelimeler kullanılarak taratılan literatürler değerlendirilmeye alınmıştır.

\section{Elektroensafalografi (EEG) Dayalı Nörofeedback} (EEG-NF) Yöntemi

EEG sinyallerinde, her biri özel fizyolojik fonksiyonları ifade eden farklı frekans bileşenleri sınıflandırılmaktadır. Özetle bu sinyaller ile bir kişi uykuda olduğunda delta dalgaları, uykulu durumunda teta dalgaları, dinlenim durumunda ve kasları gevşemiş, fakat bilinçlilik durumunda alfa dalgaları, dikkat/tetikte olma durumunda beta dalgaları, problem çözmeye çalışma durumunda gama dalgaları gözlenmektedir (1).

\section{EEG-NF Yöntemi Tedavi Protokolleri}

EEG-NF tedavi protokolleri; alfa $(\alpha)$, beta $(\beta)$, alfa/teta $(\alpha / \theta)$, delta $(\delta)$, gama $(\gamma)$, teta $(\theta)$ ve yüksek frekansa karşı düşük frekans eğitimi olmak üzere başlıca yedi temel grubu ayrilmaktadır (1).

\section{a. Alfa protokol}

Alfa eğitimi, genellikle ağrı giderimi ( $9 \mathrm{~Hz}$ uyarı ile), stres ve anksiyeteyi azaltma (10-30 Hz uyarı ile), hafıza gelişimi, zihinsel performans gelişimi ve beyin yaralanmalarının tedavisi (10,2 Hz uyarı ile) gibi çeşitli hastalıkların iyileştirilmesinde kullanılmaktadır (1). Alfa tedavisinde, meditasyon, uyku hali, stres ve anksiyete azalımı için kullanılan en yaygın frekans bant aralığı 7-10 Hz'dir. Ayrıca $10 \mathrm{~Hz}$ frekans; derin kas gevşemesi, ağrı azalması, solunum hızının düzenlenmesi ve kalp hızının azalmasina neden olmaktadır $(11,30)$. TSSB tedavisine 
dayalı birçok çalışmada da alfa eğitimi kullanılmıştır (Tablo 1) (14, 16-19, 21).

\section{b. Beta protokol}

Beta aktivitesi, mental performans için iyi bir belirteç olup, uygun olmayan beta aktivitesi depresyon, dikkat eksikliği hiperaktivite bozukluğu (DEHB) ve uykusuzluk (insomnia) gibi mental ve fiziksel bozuklukları göstermektedir (31). Beta beyin dalgaları bilinçli duyarlılık, güçlü odaklanma ve sorunları çözme yeteneği ile ilişkilidir. $\mathrm{Bu}$ nedenle beta eğitimi, dikkat ve odaklanmayı iyileştirmede (artmış 12-14 Hz uyarı), okuma yeteneğini geliştirmede (7-9 Hz uyarı), okul performansında olumlu değişimler ortaya çıkarmada kullanılmaktadır. Ayrıca bu eğitim, hesaplama performansı ve bilişsel süreçleri iyileştirir, endişe/kayg1, aşırı düşünme, obsesif-kompulsif bozukluk (OKB), alkolizm ve uykusuzluğu (insomina) azaltma (14-22 Hz ve $12-15 \mathrm{~Hz}$ uyarı), bilişsel performansı iyileştirmede (beta'nın 1şı ve ses uyarısı) etkilidir (1). Ek olarak, anksiyete, epilepsi, öfke ve stresi azaltmada 12-15 Hz (SMR: sensorimotor ritm) aralığındaki beta dalgaları kullanılır (11,31). TSSB semptomlarının ve çocukluk travması tedavisinde SMR'yi kullanmış yalnızca iki araştırma bulunmaktadır $(14,25)$ (Tablo 1).

\section{c. Alfa/teta protokol}

Alfa/teta eğitimi, stresi azaltmada en yaygın kullanılan NF eğitimlerinden biri olup, bu oran bilinçlilik ve uyku arasındaki bir belirteçtir (32). Bu tedavi yöntemi ayrıca, yaratıcılık, relaksasyon (dinlenme), müzik performansını arttırma ve travma reaksiyonlarından sonra iyileşmeye yardımcı olur iken, ağır depresyon düzeyleri, bağımlılık, anksiyete için de kullanılmaktadır. Alfa/teta özgün 7,8 Hz değeri ile 7-8,5 Hz frekans aralığındadır (1). Alfa dalga aktivitesinin dış dünyaya yönelik dikkat ve konsantrasyon arasındaki sınırdan sorumlu, teta dalga aktivitesinin ise iç dünyaya yönelik dikkatin değişimi ile ilgili olabileceği bildirilmiştir. Gözler kapalı dinlenim durumunda gerçekleştirilen alfa/teta tedavi protokolünün amac1, her iki dalganın da artmakta olduğu düşünülmesine rağmen, alfa dalgasına (8-12 Hz) göre beynin mid (orta) ve frontal bölgesindeki teta dalgasına $(4-8 \mathrm{~Hz})$ oranını arttırmaktır. Beyinde alfa dalga aktivitesi genellikle teta dalga aktivitesinden yüksektir ve TSSB semptomlarının tedavisinde alfa/teta eğitimi kullanılmıştır (Tablo 1) $(15,20,26,27)$.

\section{d. Delta protokol}

Delta dalgaları ise, uykunun 3. ve 4. evreleri ile ilişkili olan en yavaş beyin dalgalarıdır (33). Delta dalgaları, konforda artış, ağrıda azalma ve uyku durumunu göstermektedir. Bu nedenle delta eğitimi, baş ağrıları, travmatik beyin yaralanmaları ve öğrenme bozukluklarını gidermede, keskin ve şiddetli kas kasılmalarını tedavi etmede (1-3 Hz uyarı ile) kullanılmaktadır. Ayrıca bu dalgalar, endişe/kaygıyı azaltır ve uykuyu düzenler (11).

\section{e. Gama protokol}

En yüksek frekansa sahip olan gama dalgaları, hafızanın geri çağrılmasının daha hızlı olmasında görevlidir. $\mathrm{Bu}$ dalgalar, beynin nöronal bağlantıları ve diş dünyaya veri transferinden sorumlu olan hızlı ritimlerdir. $\mathrm{Bu}$ hızlı ritmler, başlıca hipokampüste kısa süreli hafızadan uzun süreli hafizaya dönüşümden sorumlu beyin bölgesinde, nöbet, spazm gibi ani ataklarda gözlenmektedir. Bu nedenle gama eğitimi, biliş, mental keskinlik, beyin aktivitesi ve problem çözme görevlerini desteklemek için kullanılır. Bu eğitim, zayıf hesaplamayı geliştirmekle birlikte, bilgi işleme hızını, kısa süreli hafızayı geliştirerek, migren ataklarının sayısını azaltarak beyni düzenler $(1,11)$.

\section{f. Teta protokol}

Teta dalgaları, hafiza, duygu, yaratıcılık, uyku, meditasyon ve hipnoz gibi bir dizi beyin aktivitesi ile ilişkilidir. $\mathrm{Bu}$ dalgalar aynı zamanda, uykunun hafif olduğu ve kişinin kolayca uykudan uyandığı uykunun ilk evresi ile ilişkilidir. Teta eğitimi, endişe, depresyon, hayal kurma, dikkat dağınıklığı, duygusal bozuklukları ve TSSB'nu azaltır (Tablo 1) (1, 11, 15, 24, 26, 27, 32).

\section{g. Yüksek frekansa karşı düşük frekans eğitimi}

NF tedavisinde, temel olarak iki klasik yön bulunmaktadır. Gevşeme ve odaklanmayı güçlendirmek için düşük frekansların (alfa veya teta) (32), aktivasyonu, organize etmeyi güçlendirmek ve dikkat dağınıklığını baskılamak için yüksek frekansların (düşük beta, beta ve teta) üzerinde durulması gerekmektedir (34).

\section{Travma Sonrası Stres Bozukluğu (TSSB)'nun EEG-} NF Yöntemi ile Tedavisine İlişkin Çalışmalar

$\mathrm{Bu}$ derlemede incelenen TSSB'da EEG-NF tedavisine yönelik literatürde yer alan 14 çalışmaya ait veriler Tablo 1 'de sunulmuştur. $\mathrm{Bu}$ çalışmalarda farklı tedavi protokollerine dayalı olarak EEG-NF yönteminin, TSSB tedavisinde değişik etki mekanizmaları üzerinde olumlu etkileri olduğu gözlenmiştir. Bu çalışmaların çoğunda, TSSB için EEG-NF tedavi protokollerinden, başlica ya tek başına alfa dalgalarının ya da alfa ve teta dalgalarının her ikisinin gücünü düzenlemek amaçlanmıştır (13). Çünkü alfa aktivitesi, genellikle sakin ve dinlenim durumları ile ilişkili bulunmaktadır. Fakat bazı araştırma bulgularına göre, TSSB hastaları, hem azalmış alfa ritmi gücüne, hem de hızlandırılmış alfa ritmi frekansına sahiptir $(35,36)$. Bu nedenle literatürde birçok çalışma, ya alfa dalgası ile birleştiren ödüller ile $(14,17,19)$, ya da alfa desenkronizasyon ile $(16,18,21)$ alfa ritminin gücünü arttırarak EEG-NF tedavisini düzenlemeyi hedeflemiştir. Alfa/teta eğitimi ise beş çalışmada kullanılmıştır $(15,20,24,26,27)$. Diğer çalışmalar ise, TSSB için alfa ve/veya teta dalgalarını hedefleyen tipik EEG-NF'in aksine, sensoriomotor ritm (SMR) eğitimini kullanmıştır (14, 23, 25). Çünkü hem duyusal (sensory), hem de motor aktiviteyi yansıtan SMR dalgalarına dayalı eğitim, artmış dikkat performansı ve azalmış motor aktivite ile ilişkili bulunmuştur (31). Ayrıca yalnızca bir çalışmada, $20 \mathrm{~Hz}$ frekansı dengeleyen standardize elektromanyetik enerji (EM) uyarımına dayalı EEG biyofeedback'in yeni bir çeşidi olan Flexyx Nöroterapi Sistemi (FNS) kullanılmıştır (Tablo 1) (22).

Askovic ve ark. (14) çalışmalarında, mülteciler ile ilişkili kronik TSSB'na sahip iki vakada EEG-NF kullanımı ve değerlendirilmesini gerçekleştirdiler. Çalışma bulgularına göre, bu hastalarda, ya SMR ya da alfa ritmini arttırmaya dayalı gerçekleştirdikleri NF tedaviden sonra TSSB semptomlarında anlamlı azalmalar ve günlük işlevlerinde iyileşmeler kazanılmıştır. Kantitatif EEG (qEEG) ölçümleri ise, bu hastaların çalışma belleği işlevi ve dinlenimde aşırı uyarılmış durumunu içeren travma ile ilişkili EEG marker'larının normalizasyonunu göstermiştir. Böylece onlar, travma ile bilgilendirilmiş tedaviye ek olarak NF yönteminin, mülteci deneyimleri 
ile ilişkili kronik TSSB'nun iyileştirilmesinde yardımcı olabileceğini ifade etmişlerdir (Tablo 1).

Noohi ve ark. (15) çalışmalarında, rastgele seçilmiş TSSB'na sahip deney grubu $(n=15)$ ve kontrol grubuna $(n=15)$ ait bireylerde alfa/teta EEG-NF tedavi protokolü uygulayarak, NF tedavinin TSSB semptomları ve gerçekleştirdikleri fonksiyonlar üzerine etki düzeylerini belirlemeyi amaçladılar. $\mathrm{Bu}$ çalışma sonucu elde edilen bulgular, EEG-NF tedavinin TSSB semptomları ve depresyon üzerinde anlamlı düzeyde iyileşmeler sağladığ 1 , bu tedavinin depresyon üzerindeki iyileşme seviyesinin TSSB semptomları üzerindeki iyileşmeden daha düşük olduğu saptanmıştır (Tablo 1).

Ros ve ark. (16) çalışmalarında alfa desenkronizasyon kapal1-döngü (EEG-NF) eğitimini takiben, beyindeki kritik dalgalanmaların intrensek (içsel) bir şekilde kendi kendini ayarlamasında yeni deneysel ve mekaniksel bir delil ortaya koymuşlardır. Bu delile göre, bozulmuş uzun mesafeli temporal bağlantılar (LRTCs: long-range temporal correlations)'a sahip olan TSSB dâhil olmak üzere şizofreni, majör depresyon ve epilepsi gibi hastalıkların tedavi uygulamalarında, NF yönteminin doğrudan katkı sağlayabileceğini ileri sürmüşlerdir. Beyin salınımları, bu salınım dalgalanmalarının düzenliliğini yansıtan ve yüksek değerler kalıcı-düzenli (ilişkili), düşük değerler rastgele (ilişkili olmayan) olarak temsil edilen LRTC'ler olarak gösterilir. LRTC'ler, beyinin nöronal aktivitelerinin düzen ve rastgelelilik arasında dengede olduğu bir duruma yakın çalıştığını destekleyen bir kanıt oluşturur. Bu çalışmada sağlıklı yetişkinlerde, alfa salınım genliğini azaltmak için NF eğitimi kullanıldığında, eğitim sonrası spontan LRTC'lerde anlamlı artışlar ortaya çıkmıştır. Bu etki, NF tedavi ile anormal rastgele dinamiklerin tersine çevrildiği TSSB'na sahip hastalarda, aşırı uyarılmışlıkta anlamlı iyileşmeler ile ilişkili olarak meydana gelmiştir. Özellikle NF ile anormal derecede düşük LRTC'leri (yani aşırı rastgeleliği) gösteren bölgeler, kendi kendini düzenleme hakkındaki teorik tahminler ile uyumlu olarak sağlıklı popülasyon seviyelerine normalize olmuştur. $\mathrm{Bu}$ nedenle bu çalışma bulgularına göre, psikiyatrik bozukluğu olan bireylerde anormal dinamikler görülmesine rağmen, uygun NF eğitim programı uygulandığında, spontan kortikal aktivitenin kendi temporal karmaşıklığını "kendi-kendine düzenleme" için rezidüel (ek) bir kapasite ortaya koymakta olduğu ileri sürülmüştür (Tablo 1).

van der Kolk ve ark. (17) çalışmalarında alfa aktivitesini arttırmaya dayalı NF tedavinin, kronik TSSB'da bozulmuş düzenleme kapasitesi etkilerini değiştirip değiştirmediğini ve dolayısıyla bu hastalığın belirtilerini (semptomatolojisi) iyileştirip iyileştirmediğini araştırmayı amaçladılar. Çalışmalarında, 28'i NF eğitimi ve kontrol grubu olarak 24'ü bekleme listesinde (WL: waitlist) olmak üzere randomize olarak toplam 52 kronik TSSB'lu birey incelenmiştir. NF tedavisi 12 hafta boyunca haftada iki kez uygulanmıştır. $\mathrm{Bu}$ incelemede, baseline-başlangıç (T1), 6. haftadan sonra (T2), tedavi sonrası (T3) ve bir aylık takipte (T4) olarak dört değerlendirme gerçekleştirmişlerdir. Başka bir deyişle onlar, çoklu travma maruziyeti olan ve TSSB tedavisi almış hastalarda TSSB semptomlarını azaltma ve olumsuz etkilenmeyi düzenlemeyi arttırmak için NF etkinliğini değerlendirmek için bu randomize, bekleme listeli küçük, kontrollü çalışmayı gerçekleştirmişlerdir. Elde edilen bulgulara göre, kontrol grup NF ile karşılaştırıldığında, bu tedavinin kronik TSSB'lu bireylerde düzenleme kapasitelerini etkilemenin yanı sıra TSSB semptomlarını iyileştirmede anlamlı sonuçlar verdiği gözlenmiştir (Tablo 1).

Nicholson ve ark. (18) çalışmalarında alfa desenkronizasyon EEG-NF yöntemi kullanarak, TSSB semptomlarını iyileştirmek için bu bozukluk ile ilişkili nöral ağları değiştirmede alfa ritminin genliğini azaltmayı amaçlamışlardır. Ayrıca amigdalanın TSSB semptomlarına aracılık eden merkezi beyin bölgelerinden biri olduğu düşünülmektedir. $\mathrm{Bu}$ nedenle onlar çalışmalarında, TSSB'lu hastalar arasında davranışsal ve alfa dalgası salınım değişiklikleri ile ilişkili olan subkortikal mekanizmaları gözlemek için EEG-NF öncesi ve sonrasında, fMRI'yi kullanarak amigdala kompleks bağlantı modellerini direkt karşılaştırmışlardır. $\mathrm{Bu}$ karşılaştırma sonucu, savunma, duyusal, korku işlenmesi/ hafıza kazanımındaki olumsuz yönde etkilenmiş bölgelerden, duygu düzenleme /modülasyonunda yer alan prefrontal alanlara kayma ile EEG-NF tedavi ilişkilendirilmiştir. Amigdala kompleks bağlantıdaki bu kaymanın, azalmış uyarılma, daha büyük dinlenim alfa senkronizasyonu (alfa desenkronizasyon) ile pozitif ve TSSB semptom şiddeti ile ise negatif olarak ilişkili olduğu gösterilmiştir. Sonuç olarak onlar, TSSB hastalarında alfa salınımlı NF kullanımının, hastalığın akut semptomlarının hafifletilmesine ek olarak, hastalıkta yüksek oranda olumsuz yönde etkilenmiş olan beyin bölgeleri arasında nöronal yeniden yapılanma gösterdiğini kanıtlamışlardır (Tablo 1).

Gapen ve ark. (19) çalışmalarında, önceden tedaviye dirençli TSSB hasta grubunda $(n=17)$, alfa aktivitesini arttırmaya dayalı EEG-NF tedavisinin hastalık semptomları üzerindeki etkisini araştırdılar. Bu çalışmada haftada iki kez uygulanan 40 NF seansın, TSSB semptomlarının anlamlı ölçüde azaltır iken, ortadan kaldırmadığı saptanmıştır. Bu bulgular, tedaviye dirençli TSSB ile çoğalan travmatize olmuş bireylerde NF tedavinin kullanımının önemini kanıtlamıştır (Tablo 1).

Rastegar ve ark. (20) tarafından gerçekleştirilen çalışmada ise, psikiyatri servislerinde yatan TSSB'lu gaziye $(n=15)$ alfa-teta EEG-NF eğitimi verilerek, bu deney grubuna uyumlu olarak NF eğitimi verilmeyen kontrol grubu $(\mathrm{n}=15)$ ile deney grubu karşılaştırılmıştır. Çalışma bulgularına göre, alfa ve teta dalgaları ilişkin NF eğitimi, sürdürülebilir dikkat testi olan sürekli performans testi (CPT: Continuous Peformance Test)'nde doğru algılamayı anlamlı derecede arttırır iken, atlama hataları, gereksiz basma hataları ve reaksiyon zamanları parametrelerinde anlamlı azalmalar sağlamıştır (Tablo 1). Kluetsh ve ark. (21) çalışmalarında, alfa desenkronizasyon EEG-NF tedavisinin TSSB'ndaki düzenleyici sistemler üzerindeki etkilerine aracılık eden olası nöro-davranışsal mekanizmaları açıklamaya çalışmışlardır. Çalışmalarında, çocukluk istismarı ile ilişkili TSSB'lu bireylerde $(n=21)$, NF tedavi seansları öncesi dinlenim EEG baseline grafikleri ile karşılaştırıldığında, 30 dakikalık NF eğitiminden sonra ortalama alfa genliğinde anlamlı azalmalar gözlenmiştir. 
Tablo 1. TSSB hastalarında EEG-NF tedavi etkinliğini inceleyen çalıșmalar ve sonuçları

\begin{tabular}{|c|c|c|c|c|c|c|c|}
\hline Araştırmaci/Yıl & $\begin{array}{l}\text { Örnek } \\
\text { Sayısı } \\
\text { (n) }\end{array}$ & Yaş (yıl) & $\begin{array}{l}\text { İlaç Tedavisi } \\
\text { (var/yok) }\end{array}$ & $\begin{array}{c}\text { Randomizasyon } \\
\text { (Rastgele Atama) } \\
\text { (var/yok) }\end{array}$ & Tedavi (NF) grubu & Kontrol grubu & $\begin{array}{l}\text { EEG-NF Tedavi } \\
\text { Sonuçları }\end{array}$ \\
\hline $\begin{array}{l}\text { Askovic ve ark. } \\
\text { /2017 (14) }\end{array}$ & 2 & $\begin{array}{c}31 \\
\text { (ortalama) }\end{array}$ & $\begin{array}{l}\text { Var } \\
\mathrm{n}=2\end{array}$ & Yok & $\begin{array}{l}\text { SMR arttırma / alfa ritmini } \\
\text { arttırma }\end{array}$ & Yok & $\begin{array}{c}\text { TSSB semptomlarında anlamlı azalma ve travma ilişkili EEG } \\
\text { marker'larının normalizasyonu saptandı. }\end{array}$ \\
\hline $\begin{array}{l}\text { Noohi ve ark. /2017 } \\
\text { (15) }\end{array}$ & 15 & $\begin{array}{c}25-60 \\
\text { (alt-üst sinır) }\end{array}$ & Bildirilmemiş & Var & Alfa/ teta eğitimi & $\begin{array}{l}\text { Sağlıklı bireyler } \\
(\mathrm{n}=15)\end{array}$ & $\begin{array}{l}\text { TSSB semptomları ve depresyon üzerinde anlamlı düzeyde } \\
\text { iyileşmeler sağlandı. }\end{array}$ \\
\hline $\begin{array}{c}\text { Ros ve ark./ } 2017 \\
\text { (16) }\end{array}$ & 21 & 39,9 (ortalama) & $\begin{array}{c}\text { Var } \\
\mathrm{n}=11\end{array}$ & Yok & Alfa desenkronizasyonu & Yok & $\begin{array}{l}\text { LRTC'ler ile TSSB'nda anormal rastgele dinamiklerin tersine } \\
\text { çevrilmesi ve aşırı uyarılmışlıkta anlamlı iyileşmeler gözlendi. }\end{array}$ \\
\hline $\begin{array}{l}\text { Van der Kolk ve } \\
\text { ark./ } 2016 \text { (17) }\end{array}$ & 28 & $\begin{array}{c}46 \\
\text { (ortalama) }\end{array}$ & $\begin{array}{c}\text { Var } \\
\mathrm{n}=16 \text { (NF) } \\
\mathrm{n}=10 \text { (Bekleme listesi) }\end{array}$ & Var & Alfa aktivitesini arttırma & $\begin{array}{l}\text { Bekleme } \\
\text { Listesi } \\
(\mathrm{n}=24)\end{array}$ & $\begin{array}{l}\text { TSSB düzenleme kapasitelerini etkileme ve semptomlarını } \\
\text { iyileştirdi. }\end{array}$ \\
\hline $\begin{array}{l}\text { Nicholson ve ark. } \\
\text { /2016 (18) }\end{array}$ & 21 & 39,9 (ortalama) & $\begin{array}{c}\text { Var } \\
\mathrm{n}=11\end{array}$ & Yok & Alfa desenkronizasyonu & Yok & Amigdala kompleks bağlantıda kaymalar gözlendi. \\
\hline $\begin{array}{l}\text { Gapen ve ark./ } 2016 \\
\text { (19) }\end{array}$ & 17 & $\begin{array}{c}32-64 \\
\text { (alt-üst sinır) }\end{array}$ & $\begin{array}{c}\text { Var } \\
\text { (n bildirilmemiş) }\end{array}$ & Var & Alfa aktivitesini arttırma & Aktif & $\begin{array}{c}\text { TSSB semptomlarının önemli ölçüde azaltır iken ortadan } \\
\text { kaldırmadığı saptandı. }\end{array}$ \\
\hline $\begin{array}{l}\text { Rastegar et. al./ } \\
\quad 2016(20)\end{array}$ & 15 & $\begin{array}{c}40-60 \\
\text { (alt-üst sınır) }\end{array}$ & $\begin{array}{c}\mathrm{Var} \\
\text { (n bildirilmemiş) }\end{array}$ & Var & Alfa/ teta eğitimi & $\begin{array}{l}\text { NF eğitimi almayan } \\
\text { bireyler } \quad(n=15)\end{array}$ & $\begin{array}{l}\text { NF eğitimi, CPT'de doğru algılamayı anlamlı derecede arttıırı iken, } \\
\text { atlama hataları, gereksiz basma hataları ve reaksiyon zamanlarında } \\
\text { anlamlı azalmalar sağladı. }\end{array}$ \\
\hline $\begin{array}{l}\text { Kluetsch ve ark./ } \\
2014 \text { (21) }\end{array}$ & 21 & 39,9 (ortalama) & $\begin{array}{l}\text { Var } n=11 \\
\text { Yok } n=10\end{array}$ & Yok & Alfa desenkronizasyonu & Yok & $\begin{array}{l}\text { EEG-NF tedavi sonrası, anlamlı alfa ritmi “"geri sıçraması } \\
\text { (rebound)"nın, TSSB'nda artan sakinlik ile ilişkili olduğu } \\
\text { saptand.. }\end{array}$ \\
\hline $\begin{array}{l}\text { Nelson ve Esty/ } \\
2012 \text { (22) }\end{array}$ & 7 & $\begin{array}{c}23-42 \\
\text { (alt-üst sinır) }\end{array}$ & Yok & Yok & $\begin{array}{l}20 \mathrm{~Hz} \text { frekansı dengeleyen } \\
\text { elektromanyetik (EM) enerji } \\
\text { uyarımı ile standardize } \\
\text { edildi. }\end{array}$ & Yok & $\begin{array}{l}\text { Afganistan / Irak savaş gazilerine Flexyx Nöroterapi Sistemi (FNS) } \\
\text { ad verilen yeni bir EEG biyofeedback çeşidi uygulanmass ile } \\
\text { TSSB semptomlarında anlamlı azalmalar meydana geldi. }\end{array}$ \\
\hline $\begin{array}{c}\text { Othmer ve Othmer/ } \\
2009(23)\end{array}$ & 2 & Bildirilmemiş & $\begin{array}{l}\text { Var } \\
\mathrm{n}=2\end{array}$ & Yok & SMR alfa/beta eğitimi & Yok & $\begin{array}{l}\text { TSSB semptomlarının iyileştirilmesinde özellikle düşük } \\
\text { frekansların ( } 0,1 \mathrm{~Hz} \text { 'e kadar düşük) faydalı olduğu gösterildi. }\end{array}$ \\
\hline Smith/ 2008 (24) & 10 & $\begin{array}{l}26-63 \\
\text { (alt-üst sinır) }\end{array}$ & $\begin{array}{l}\text { Var } \\
\mathrm{n}=3\end{array}$ & Yok & $\begin{array}{c}\text { İki aşamalı } \\
\text { 1)Bipolar üst eğitim } \\
\text { (15-18 Hz ve 12-15 Hz) + } \\
\text { teta (4-7 Hz) baskılanması } \\
\text { 2)Bipolar üsteğitimi takiben } \\
\text { alfa/teta }(5-8 \mathrm{~Hz}) \text { eğitimi } \\
\end{array}$ & Yok & $\begin{array}{l}\text { NF tedavi sonrası HAMD ölçeğinde anlamlı azalmalar ile } \\
\text { TOVA'da olumlu değişimleri sonucu TSSB belirtileri üzerinde } \\
\text { anlamlı ve büyük azalma gösteren pozitif klinik etkiye sahip } \\
\text { olduğu belirlendi. }\end{array}$ \\
\hline $\begin{array}{l}\text { Pop-Jordanova ve } \\
\text { Zorcec/2004 (25) }\end{array}$ & 10 & 9 (ortalama) & Yok & Yok & SMR & Yok & $\begin{array}{l}\text { EDR / EEG biyofeedback (haftada } 50 \text { dakikalık bir seans) } \\
\text { tedaviden sonra TSSB semptomlarının ortadan kalktığı gözlendi. }\end{array}$ \\
\hline $\begin{array}{l}\text { Peniston ve ark./ } \\
1993 \text { (26) }\end{array}$ & 20 & 37,2 (ortalama) & Bildirilmemiş & Yok & Alfa/teta eğitimi & Yok & $\begin{array}{c}\text { NF seans sonrası beyin senkronizasyonunda artış, son NF seansı } \\
\text { boyunca teta dalgalarının kademeli olarak artış, alfa dalgalarında } \\
\text { azalmanın olduğu çapraz bir model gözlendi. }\end{array}$ \\
\hline $\begin{array}{c}\text { Peniston ve } \\
\text { Kulkosky/ } 1991 \text { (27) }\end{array}$ & 29 & $\begin{array}{c}37,25 \\
\text { (ortalama) }\end{array}$ & $\begin{array}{c}\text { Var } \\
\mathrm{n}=29\end{array}$ & Var & Alfa/teta eğitimi & $\begin{array}{l}\text { Geleneksel Tibbi } \\
\text { Kontrol } \\
(\mathrm{n}=14)\end{array}$ & $\begin{array}{l}\text { Kronik TSSB tedavisi ve semptomların tekrarlanmasının } \\
\text { önlenmesinde etkili olduğu ve } 13 \text { MMPI ölçeğinde kontrol grubuna } \\
\text { göre anlamlı derecede daha fazla düzelme olduğu saptandı. }\end{array}$ \\
\hline
\end{tabular}

CPT: Continuous Peformance Test; EDR; Electrodermal response; EEG: Electroencephalography; HAMD: Hamilton Depression Rating Scale; LRTCs: Long-Range Temporal Correlations; MMPI: Minnesota

Multiphasic Personality Inventory; NF: Neurofeedback; SMR: Sensorimotor ritm; TOVA: Test of Variable of Attention 
Böylece, alfa desenkronizasyon NF'in, dinlenim durumu alfa senkronizasyonunda anlamlı bir artışın ("geri sıçrama (rebound)'") ardından, NF tedavi boyunca azalmış alfa genliği (amplitüdü) ile ilişkili olduğu bulunmuştur. Ayrıca EEG-NF tedavi sonrası, anlamlı alfa ritmi “'geri sıçraması'”nın, TSSB'nda artan sakinlik ile ilişkili olduğu saptanmıştır. $\mathrm{Bu}$ bulgulara göre, NF eğitimi boyunca azalmış alfa amplitüdünün, NF tedavi sonrasında travma sonrası alfa "geri sıçrama (rebound)", ile ilişkili olduğunu ve artmış dinlenim alfa senkronizasyonun ise TSSB'nda biliş ile ve dolaylı olarak beyin ağ bağlantılarında değişiklikler ile ilişkili olduğunu belirlemişlerdir. Böylece çalışmalarında, ilk kez NF sonrası spontan EEG “'geri sıçrama'”nın beyindeki homeostatik/dengeleyici mekanizmaları işaret ettiğini ve EEG-NF yöntemimin bu bölgeleri istemli olarak hemen iyileştirdiğini ortaya koymuşlardır (Tablo 1).

Nelson ve Esty (22) çalışmalarında, tedaviye dirençli TSSB'lu Afganistan / Irak savaş gazilerine (n=7) Flexyx Nöroterapi Sistemi (FNS) adı verilen $20 \mathrm{~Hz}$ frekansı dengeleyen standardize elektromanyetik enerji (EM) uyarımına dayalı yeni bir EEG biyofeedback çeşidi uygulamışlardır. Bu uygulama, gazilerin rahatsız edici nörodavranışsal ve TSSB semptomlarında anlamlı azalmalar meydana getirmiştir. $\mathrm{Bu}$ sonuçlar, FNS'nin karışık travma spektrum sendromlarının iyileştirilmesine yardımcı olabileceğini göstermiştir (Tablo 1).

Othmer ve Othmer (23) çalışmalarında, hastalık öykü geçmişine sahip iki TSSB'lu gazi vakalarına, fonksiyonel iyileşmeye yardımcı olmak için 24 seanstan oluşan SMR alfa/beta eğitimine dayalı EEG-NF eğitimi uygulamışlardır. $\mathrm{Bu}$ çalışmada, TSSB semptomlarının iyileştirilmesinde özellikle düşük frekansların $(0,1 \mathrm{~Hz}$ 'e kadar düşük) faydalı olduğu gösterilmiştir (Tablo 1).

Smith (24) çalışmasında, depresyona neden olduğu ve dikkat seviyelerinin azaldığını gösteren TSSB'na sahip asker gazilerinde $(n=10)$, alfa/teta ve teta olmak üzere iki aşamalı EEG-NF tedavi protokolünün uygulanması sonucu gazilerin dikkat seviyelerinde artış, depresyon semptomları ve TSSB belirtileri (semptomatolojisi) üzerinde anlamlı ve büyük azalma gösteren pozitif klinik etkiler belirlemiştir. Çünkü çalışma bulgularında, EEGNF tedavi ile Hamilton Depresyon Derecelendirme Ölçeği (HAMD: Hamilton Depression Rating Scale)'nde anlamlı azalmalar ve Dikkat Değişkeni Testi (TOVA: Test of Variable of Attention) sonuçlarında olumlu değişimler saptanmıştır (Tablo 1).

Pop- Jordanova ve Zorcec'in (25) çalışmalarının amacı, erken çocukluk döneminde bağlanma kalitesi ve çocukluk travması arasındaki ilişkiyi araştırmak ve çocukluk çağı travmasının etkileriyle ilişkili bağlanma sorunlarını gidermek için olası mekanizma olarak biyofeedback tedavisinin rolünü ortaya koymaktı. Bu bağlamda, onlar TSSB'na sahip çocuklara $(n=10$, yaş ortalamaları:9) TSSB için klasik tedaviye (bilişsel-davranışçı terapi ve oyun terapisine) ek olarak, TSSB'nun tedavisi ve etkilerinin değerlendirilmesi için çok modelli biyofeedback yöntemlerini (elektrodermal (EDR: electrodermal response) ve nörofeedback (NF)) uyguladilar. Tüm çocuklarda 20 seans EDR/EEG biyofeedback (haftada 50 dakikalık bir seans) tedaviden sonra, TSSB semptomlarının ortadan kalktığı gözlenmiştir. Böylece araştırmacılar tarafından biyofeedback teknikleri ile elde edilen tedavi edici sonuçların TSSB için ümit verici olduğu ifade edilmiştir. Ayrıca çalışmadaki tüm çocuklarda, yaşamın erken döneminde TSSB gözlendiği ve klinik tablolarının ise travmanın gerçek düzeyine göre orantısız bir şekilde daha yüksek olduğu gözlenmiştir. Bu durumun, bu çocukların tümünde güvensiz erken bağlanma sorunu ile ilişkili olduğunu ve sosyal koşulların (savaş, ekonomik güç) ise TSSB oluşumunda ek bir temel oluşturduğunu göstermiştir. Ayrıca bu çocukların tümünde, güvensiz erken bağlanma ile tutarlı olan gelişmemiş sağ orbitofrontal korteks (ROFC: right orbito-frontal cortices) yapıları yanı sıra, devam eden davranışsal sorunlar (saldırganlık, kaygı ve stres) bulunduğu tespit edilmiştir (Tablo 1).

Peniston ve ark. (26) çalışmalarında TSSB'na sahip olma ve alkolün aşırı kullanımı ile mücadele eden Vietnam gazilerinde $(\mathrm{n}=20)$, alfa/teta EEG-NF seans uygulamaları sonraki ölçümlerde, öncesi ölçümlere göre başarılı bir beyin senkronizasyon artışı gözlemişlerdir. Ayrıca, aynı çalışmada, son NF seansı boyunca teta dalgalarının kademeli olarak arttığı, alfa dalgalarının azaldığ çaprazlama bir model saptanmıştır. Bir beyin dalgasından diğerine ilerleme, başka bir deyişle alfa dalgasındaki azalma, teta dalgasındaki artış, uyanıklık durumundan uyku durumuna geçiş olduğunda doğal olarak gerçekleşmektedir. $\mathrm{Bu}$ çalışmanın bulgularına göre alfa/teta EEG-NF eğitimi ile kabus/karabasan, geri çağrışımı (flashbacks) tetikleyen anksiyete'de anlamlı azalmalar gerçekleşmiş ve sadece dört katılımcının TSSB ve semptomları 26 ay sonra tekrarlamıştır. Araştırmadaki katılımcıların çoğu $(n=16)$ ise, NF tedavi sırası ve sonrasında, travma ile ilişkili hatıralarında önemli ölçüde korku duymadıklarını bildirmişlerdir (Tablo 1).

Peniston ve Kulkosky (27) çalışmalarında, kronik TSSB ile mücadele eden Vietnam gazilerinden $(n=29)$ rastgele seçilen 15 hastaya alfa/teta EEG-NF uygulaması, diğer 14 hastaya ise, araştırmada kontrol grubu olarak yalnızca geleneksel tıbbi tedavi (psikotrop ilaçlar (trisiklik antidepresanlar, antipsikotikler ve anksiyolitikler), bireysel ve grup terapisi) verilmesi sağlanmış, EEG-NF tedavinin TSSB'nun tedavisinde başarılı olduğu gösterilmiştir. Çalışma bulgularına göre, 30 aylık bir takip süresi boyunca geleneksel ilaç tedavisi alan kontrol grubundaki katılımcıların tümünde (\%100) bu semptomlar tekrar geri gelir iken, EEG-NF tedavi alan 15 hastanın yalnızca üçünde TSSB semptomlarının tekrarlamış olduğu gözlenmiştir. Ayrıca, bu çalışmada 13 Minnesota Çok Yönlü Kişilik Envanter (MMPI: Minnesota Multiphasic Personality Inventory) ölçeğinde EEG-NF grubunun, kontrol grubuna göre anlamlı derecede daha fazla düzelme gösterdiği saptanmıştır. Sonuç olarak çalışma bulguları, alfa/teta EEG-NF uygulamasinın TSSB tedavisinde ve semptomların tekrarlanmasının önlenmesinde etkili bir tedavi olduğu göstermiştir (Tablo 1).

\section{NF Tedavinin Altında Yatan Mekanizmalara Ait} Hipotezler

NF'in nasıl çalıştığının delili ve beyin fonksiyonları üzerinde NF'in etkisi halen bilinmemektedir. Fakat farklı hipotezler ortaya atılmıştır (37). Nöroplastisite, beyin görüntüleme yöntemleri ve araştırmalar tarafindan desteklenmiş olan bir kavramdır. Nöroplastisite, hızlı 
olarak gelişen çocuk veya ergen beyninde özellikle belirgin bir olaydır ve eğer beynin bir kısmı için fiziksel bir travma olayı meydana gelir ise, diğer bölgeler daha sonra o bölgenin görevini üstlenir. $\mathrm{Bu}$ değişiklikleri başarmak için daha fazla çaba ve bilişsel eğitim olmasına rağmen, yetişkinler plastisite tedbirine sahip olmaya devam etmektedir (10). NF, hem sinaptik seviyede, hem de güçlendirilmiş beyin devreleri yoluyla etkileri oluşturabilir ve direkt olarak normal/anormal beyin dalga titreşimleri (salınımlarını) düzenleyebilir (34, 38, 39). Ayrıca NF eğitiminden sonra, MRI yöntemi ile beynin beyaz ve gri cevherde meydana gelmiş olan mikroyapısal değişiklikler belirlenmiştir (38). Aslında NF'in fonksiyonel ve anatomik olarak spesifik beyin değişikliklerine neden olabileceği öngörülmektedir (37). $\mathrm{Bu}$ değişikliklerin, beyin rahatsızlıklarının geniş bir bölümünün etkilenmiş olduğu fonksiyon bozukluğunun olduğu merkezi nöro-bilişsel ağlarda (network) ortaya çıktığı gösterilmiş ve psikopatolojinin temelini oluşturduğu önerilmiştir (üçlü network model) $(34,40)$. Fakat EEG-NF tedavisinin nöropskiyatrik hastalıkların altında yatan patofizyolojik mekanizmaları nasıl etkilediğine dayalı kesin ve net bir açıklama bulunmamaktadır.

\section{SONUC VE ÖNERİLER}

$\mathrm{Bu}$ derlemede, değişik tedavi protokollerine bağlı olarak, farklı olası etki mekanizmaları üzerinden EEG-NF yönteminin uygulanmasının, TSSB tedavisi ve semptomlarının iyileştirilmesi üzerinde anlamlı derecede olumlu etkiler gösterdiği belirlenmiştir. Bu nedenle TSSB gibi nöropskiyatrik bozukluklarda EEG-NF tedavisinin alternatif bir tedavi yöntemi olarak ümit verici olduğu düşünülmektedir. Fakat gelecek araştırmalarda EEG-NF yöntemimin TSSB tedavisi üzerinde kesin etki mekanizmalarını ortaya koyabilmek ve bireye ve/veya hastalığın semptomlarına özgü standardize tedavi protokollerini belirleyebilmek, ilaç kullanımı, terapist hasta özellikleri ve diğer terapötik süreçler gibi TSSB tedavisine etki edebilecek diğer faktörleri de hesaba katarak, EEG-NF tedavisi ve semptomları üzerinde uzun süreli olumlu etkisinin araştırılmasına yönelik, daha kapsamlı kontrollü çalışmaların yapılması hedeflenmelidir.

\section{KAYNAKLAR}

1. Marzbani H, Marateb HM, Mansouria M. Methodological note: neurofeedback: a comprehensive review on system design, methodology and clinical applications. Basic Clin Neurosci. 2016; 7(2): 143-58.

2. Gruzelier JH, Thompson T, Redding E, Brandt R, Steffert T. Application of alpha/theta neurofeedback and heart rate variability training to young contemporary dancers: state anxiety and creativity. Int J Psychophysiol. 2014; 93(1): 105-11.

3. Harris S. An Investigation of the effects of neurofeedback training on attention deficithyperactivity disorder (ADHD) symptoms, depression, anxiety, and academic self-efficacy in college students [PhD dissertations]. Orlando: University of Central Florida; 2017.
4. Little BD. Evaluating the effectiveness of a schoolbased neurofeedback intervention on decreasing anxiety in an adolescent female. The Chicago School of Professional Psychology [PhD dissertations]. Chicago: the Chicago School of Professional Psychology; 2015.

5. Schoenberg PL, David AS. Biofeedback for psychiatric disorders: a systematic review. Appl Psychophysiol Biofeed. 2014; 39(2): 109-35.

6. Foldes ST, Weber DJ, Collinger JL. MEG-based neurofeedback for hand rehabilitation. J Neuroeng Rehabil. 2015; 12: 85.

7. Thibault RT, MacPherson A, Lifshitz M, Roth RR, Raz A. Neurofeedback with fMRI: a critical systematic review. NeuroImage. 2018; 172: 786-807.

8. Liu N, Cliffer S, Pradhan AH, Lightbody A, Hall SS, Reiss AL. Optical-imaging-based neurofeedback to enhance therapeutic intervention in adolescents with autism: Methodology and initial data. Neurophotonics. 2017; 4(1): 011003.

9. Mano M, Lécuyer A, Bannier E, Perronnet L, Noorzadeh S, Barillot C. How to build a hybrid neurofeedback platform combining EEG and fMRI. Front Neurosci. 2017; 11: 140.

10. Demos JN. Getting started with neurofeedback (1st ed, Vol 1). New York: W.W. Norton \& Company; 2005.

11. Vernon DJ. Can neurofeedback training enhance performance? An evaluation of the evidence with implications for future research. Appl Psychophysiol Biofeedback. 2005; 30(4): 347-64.

12. Hammond DC. What is neurofeedback: an update? J Neurother. 2011; 15(4): 305-36.

13. Chiba T, Kanazawa T, Koizumi A, Ide $K$, Taschereau-Dumouchel V, Boku S, Hishimoto A, Shirakawa M, Sora I, Lau H, Yoneda H, Kawato M. Current status of neurofeedback for post-traumatic stress disorder: a systematic review and the possibility of decoded neurofeedback. Front Hum Neurosci. 2019; 13: 233.

14. Askovic M, Watters AJ, Aroche J, Harris AWF. Neurofeedback as an adjunct therapy for treatment of chronic posttraumatic stress disorder related to refugee trauma and torture experiences: two case studies. Australas Psychiatry. 2017; 25(4): 358-63.

15. Noohi S, Miraghaie AM, Arabi A, Nooripour R. Effectiveness of neuro-feedback treatment with alpha/theta method on PTSD symptoms and their executing function. Biomed Res. 2017; 28(5): 201927.

16. Ros T, Frewen P, Théberge J, Michela A, Kluetsch R, Mueller A, et al. Neurofeedback tunes scale-free dynamics in spontaneous brain activity. Cereb Cortex. 2017; 27(10): 4911-22.

17. van der Kolk BA, Hodgdon H, Gapen M, Musicaro R, Suvak MK, Hamlin E, et al. A randomized controlled study of neurofeedback for chronic PTSD. PLoS One. 2016; 11(12): e0166752.

18. Nicholson AA, Ros T, Frewen PA, Densmore M, Théberge J, Kluetsch RC, et al. Alpha oscillation neurofeedback modulates amygdala complex connectivity and arousal in posttraumatic stress disorder. Neuroimage Clin. 2016; 12: 506-16. 
19. Gapen M, van der Kolk BA, Hamlin E, Hirshberg L, Suvak M, Spinazzola J. A Pilot study of neurofeedback for chronic PTSD. Appl Psychophysiol Biofeedback. 2016; 41(3): 251-61.

20. Rastegar N, Dolatshahi B, Rezaei ED. The Effect of neurofeedback training on increasing sustained attention in veterans with posttraumatic stress disorder. J Pract Clin Psychol. 2016; 4(2): 97-104.

21. Kluetsch RC, Ros T, Théberge J, Frewen PA, Calhoun VD, Schmahl C, et al. Plastic modulation of PTSD resting-state networks and subjective wellbeing by EEG neurofeedback. Acta. Psychiatr Scand. 2014; 130(2): 123-36.

22. Nelson DV, Esty ML. Neurotherapy of traumatic brain injury/posttraumatic stress symptoms in OEF/OIF veterans. J Neuropsychiatry Clin Neurosci. 2012; 24(2): 237-40.

23. Othmer S, Othmer S. Post traumatic stress disorderthe neurofeedback remedy. Biofeedback. 2009; 37(1): 3-4.

24. Smith WD. The effect of neurofeedback training on PTSD symptoms of depression and attention problems among military veterans $[\mathrm{PhD}$ dissertations]. Minneapolis: Capella University; 2008.

25. Pop-Jordanova N, Zorcec T. Child trauma, attachment and biofeedback mitigation. Prilozi. 2004; 25(1-2): 103-14.

26. Peniston EG, Marrinan DA, Deming WA, Kulkosky PJ. EEG alpha-theta brainwave synchronization in Vietnam theater veterans with combat-related posttraumatic stress disorder and alcohol abuse. Adv Med Psychother. 1993; 6: 37-50.

27. Peniston EG, Kulkosky PJ. Alpha-theta brainwave neuro-feedback for Vietnam veterans with combatrelated post-traumatic stress disorder. Med Psychother. 1991; 4: 47-60.

28. American Psychiatric Association. Diagnostic and Statistical Manual of Mental Disorders (DSM-5®). Arlington: American Psychiatric Pub; 2013.

29. Schnurr PP, Friedman MJ, Engel CC, Foa EB, Shea MT, Chow BK, et al. Cognitive behavioral therapy for posttraumatic stress disorder in women: a randomized controlled trial. JAMA. 2007; 297(8): 820-30.

30. Dempster T. An investigation into the optimum training paradigm for alpha electroencephalographic biofeedback [PhD dissertations]. Canterbury: Canterbury Christ Church University; 2012.

31. Egner T, Gruzelier JH. EEG biofeedback of low beta band components: frequency-specific effects on variables of attention and event-related brain potentials. Clin Neurophysiol. 2004; 115(1): 131-9.

32. Gruzelier J. A theory of alpha/theta neurofeedback, creative performance enhancement, long distance functional connectivity and psychological integration. Cogn Process. 2009; 10(1): 101-9.

33. Surmeli T, Ertem A, Eralp E, Kos IH. Schizophrenia and the efficacy of qEEG-guided neurofeedback treatment: a clinical case series. Clin EEG Neurosci. 2012; 43(2): 133-44.

34. Ros T, Theberge J, Frewen PA, Kluetsch R, Densmore M, Calhoun VD, et al. Mind over chatter: plastic up-regulation of the fMRI salience network directly after EEG neurofeedback. Neuroimage.2013; 65: 324-35.

35. Jokic-begi'c N, Begíc, D. Quantitative electroencephalogram (qEEG) in combat veterans with post-traumatic stress disorder (PTSD). Nord J Psychiatry. 2003; 57(5): 351-5.

36. Wahbeh H, Oken BS. Peak high-frequency HRV and peak alpha frequency higher in PTSD. Appl Psychophysiol Biofeedback. 2013; 38(1): 57-69.

37. Reiter K, Andersen SB, Carlsson J. Neurofeedback treatment and posttraumatic stress disorder: effectiveness of neurofeedback on posttraumatic stress disorder and the optimal choice of protocol. J Nerv Ment Dis. 2016; 204(2): 69-77.

38. Ghaziri J, Tucholka A, Larue V, Blanchette-Sylvestre M, Reyburn G, Gilbert G, et al. Neurofeedback training induces changes in white and gray matter. Clin EEG Neurosci. 2013; 44(4): 265-72.

39. Niv S. Clinical efficacy and potential mechanisms of neurofeedback. Pers Individual Differences. 2013; 54(6): 676-86.

40. Menon V. Large-scale brain networks and psychopathology: a unifying triple network model. Trends Cogn Sci. 2011; 15(10): 483-506. 